\title{
COMMON DEFICIENCIES RAISED BY VARIOUS REGULATORY AGENCIES
}

\author{
Available online at www.ijdra.com \\ REVIEW ARTICLE \\ ${ }^{1}$ Mohidekar S*, ${ }^{1}$ Maharao V, ${ }^{2}$ Badjatya J.K. \\ ${ }^{1}$ Institute of Pharmaceutical Management, Dombivli, India \\ ${ }^{2}$ Montajat Pharmaceuticals Co. Ltd., Dammam, KSA \\ *Corresponding Author's E-mail: pharmainstitute@gmail.com
}

\section{ABSTRACT}

Timely Product registration is a challenge in today's scenario. Regulatory agencies are keen in assessing CTD sections like redefining starting material of Drug substance manufacturing, Pharmaceutical development, impurities in Drug substance and Drug product, Container-closure. Common deficiencies are presented in this article.

Keywords: Deficiencies; starting material; Impurities; ICH CTD.

\section{INTRODUCTION}

- Drugs which are marketed, distributed \& used in any country should be registered with the national competent regulatory authority. Company success depends on reduction of time taken for a drug to reach market.

- Thus, Drug registration is essential factor of drug regulation. Every drug before getting market approval undergoes rigorous scrutiny and clinical trials to ensure its Safety, Efficacy \& Quality.

- Few deficiencies raised on ICH CTD Module 3 (Quality) are depicted in the article for reference of readers.

\section{DRUG SUBSTANCE DEFICIENCIES:}

1. State if the blending of batches occurs during the proposed manufacturing process. If blending does occur, confirm that each batch will be fully tested and shown to comply with the approved API specification prior to blending.

2. State if the recovery of any solvents occurs and give the detail recovery process along with the specification of recovered solvents

3. The molecule $\mathrm{XXX}$ is not acceptable as a starting material and it should be considered as a late intermediate in the synthetic process of the final API. You are requested to redefine the starting material to a simpler molecule (as a synthetic precursor that is several synthetic steps prior to the final key intermediate).

4. The applicant's specifications for the starting material YYY are not acceptable: the specifications should contain limits for unspecified, specified and total impurities.

5. Absence of discussion for Class 1 solvent as contaminant of another solvent. (1)

6. A specific discussion as part of overall discussion on impurities should be provided with regard to Impurities with potential genotoxicity either produced by preparation of API or its degradation [reference guidance EMEA/CHMP/QWP/251344/206 or USFDA recommended approaches December 2008]. (2)

7. The limits set for residual solvents should be tightened on the basis of actual results

8. Absence of comparison of the quality of the final substance obtained with starting materials from different suppliers.

\section{DRUG PRODUCT DEFICIENCIES:}

1. Please provide the percentage, function and grade of each Excipient in the formulation

2. Justification of overages (if not provided appropriately and not scientifically justified)

3. The applicant is requested to provide information for all ingredients including 
specifications and CoA's

4. Provide a detailed description of the stages of manufacturing at which sampling is performed for In-process controls.

5. The blend sampling plan for testing the blend on the first 3 production lots is not acceptable. Agency recommends that the blend uniformity for products with low percentage of drug should be done for at least 10 lots.

6. Provide the specifications for routine release testing of the drug product and ensure that all critical quality attributes (CQA) are included in the specifications.

7. Provide 'Justification of specifications' related to control of process impurities in the drug product.

8. To reduce confusion between the net quantity statement and the strength, please relocate the net quantity statement so that it appears away from the product strength and ensure that it appears sufficiently prominent.

9. Provide extractable and leachable testing for the stopper or other container materials.

10. Provide analytical methods for detection of the extractables and leachables from the container closure system.

11. Provide moisture permeation studies for products in blister packages. (3)

\section{CONCLUSION}

Thus, with this information, the approach of regulatory agencies can be understood. We also need to refer to ICH Quality guidelines and other regional guidance to make Quality submission by providing adequate and accurate data.

\section{ACKNOWLEDGEMENT}

I take this opportunity to express my deep sense of gratitude to $\mathrm{V}$. Maharao, Institute of Pharmaceutical Management, Dombivli, India for his encouragement, guidance and inspiration.
Authors declare that there are no conflicts of interest.

\section{REFERENCES}

1. Edqm.eu [Internet]. Strasbourg: Certification of Substances Division; 2012 June [updated 2011; cited 2014 April 20]. Available from: http://www.edqm.eu/site/paphcep_12_15pdf-en30964-2.html

2. GphAonline [Internet]. Washington, DC: Generic Pharmaceutical Association; 2014 [updated 2014 March 24; cited 2014 April 24]. Available from: http://www.gphaonline.org/media/cms/Enhancing_A NDA_Submissions-A_GPhA_White_Paper.pdf

3. apps.who.int [Internet]. Geneva: World Health Organization; 2014 [updated 2014; cited 2014 April 27]. Available from: http://apps.who.int/prequal/trainingresources/pq_pres 14_PQ_AssessmentTraining/2-2\%20Common\%20 FPP\%20deficiencies.ppt 